Tohoku J. exp. Mod., 1966, 90, 291-301

\title{
Influence of Host Conditions upon the Growth Pattern of Transplanted Tumors
}

\author{
Iwao Yamaguchi, Toshio Takahashi, Tomio Narisawa, \\ Katsumi Karube and Susumu Majima \\ Department of Surgery (Prof. T. Maki), \\ Tohoku University School of Medicine, Sendai
}

\begin{abstract}
Clinical observations show that the morphological pattern of carcinoma at its advancing margin is an indication of its growth potential and is related to the prognosis of the patient. As an experimental approach to the factors determining the growth pattern of carcinoma, three transplantable mouse tumors (a spontaneous C3H mammary carcinoma, Bashford carcinoma 63 and Ehrlich ascites tumor) were observed for their growth in the subcutaneous tissue of untreated recipients and of those treated with typhoid vaccine, prednisolone or chloroquine. In the untreated animals, each of these tumors exhibited a specific pattern of the advancing margin, the tendency toward infiltrative growth being greatest in Ehrlich ascites tumor and least in the mammary carcinoma. But, common to these three tumors, the treatment with typhoid vaccine led to a less infiltrating tendency of the advancing margin, as evidenced by better defined tumor boundaries and development of thicker and denser peritumoral connective tissues, and those with prednisolone or chloroquine to a little more infiltrating tendency than in the control. This suggests that the morphological pattern of tumor growth is not fully inherent to each tumor but subject to considerable change according to the condition of the host, probably reflecting the activity of the reticuloendothelial system.
\end{abstract}

In a preceding paper $^{1}$ we described that recurrence at the regional lymph nodes of transplanted and subsequently resected MH 134 tumor was significantly decreased in frequency by the treatment of the host with typhoid vaccine, and a little increased by treatment with prednisolone. Histological studies were made of metastasized and non-metastasized lymph nodes to elucidate the phenomenon, and the conclusion was that the above mentioned treatments accelerated or inhibited, respectively, reticulosis of the nodes and thus modified their susceptibility to metastasis of the tumor. The present experiments were undertaken to examine, if such treatments of the host also influence the growth pattern of transplanted tumors. Three kinds of transplantable mouse tumors, with different growth potentials, were histologically studied for their growth in

Received for publication, June 22, 1966.

Presented at the 24th Annual Meeting of the Japanese Cancer Association, Fukuoka, October, 1965. 
variously treated hosts, with special regard to the morphological pattern of the advancing margin.

\section{Materials and Methods}

Materials. The transplantable tumors and their recipients used in the present experiments were (1) a spontaneous mammary carcinoma developing in a female $\mathrm{C} 3 \mathrm{H} / \mathrm{HeN}$ mouse, to adult female mice of the same strain, (2) Bashford carcinoma 63 supplied through courtesy of Research Laboratory, Shionogi \& Co., Osaka, to adult male dd-mice; and (3) Ehrlich ascites tumor maintained at Cancer Research Laboratory (Director: Prof. H. Sato), Research Institute for Tuberculosis, Leprosy and Cancer, Tohoku University, to adult male dd-mice.

Method of inoculation. The tumors were inoculated in the form of cell suspension to subcutaneous tissue of the recipients, at the middle of the dorsal midline. Methods for preparation of the cell suspensions and the doses were as follows: (1) fresh tissue of the mammary carcinoma, weighing $2.1 \mathrm{~g}$, was mashed by a tissue-press and mixed with $10 \mathrm{ml}$ of sterile isotonic saline to make a homogeneous suspension, $0.2 \mathrm{ml}$ each of which was inoculated to the recipients by a hypodermic syringe; (2) the Bashford carcinoma 63 , weighing $3.5 \mathrm{~g}$, was similarly treated and prepared into a saline suspension amounting to $17 \mathrm{ml}$, injection dose being $0.3 \mathrm{ml}$ per capita; and (3) ascites of a mouse bearing Ehrlich ascites tumor was diluted with saline to $10^{7}$ tumor cells per ml, injection dose being $0.1 \mathrm{ml}$ or $10^{6}$ cells per capita.

Treatment of recipients. The recipients of each of the above three tumors were divided into four groups according to the treatment to modify the environmental condition for tumor growth. Mice of Group I received no particular treatments other than tumor inoculation, and served as controls. Mice of Group II were injected intraperitoneally with $0.2 \mathrm{ml}$ each of typhoid-paratyphoid vaccine (J.P.) five days prior to tumor inoculation, on the day of tumor inoculation, and five and ten days thereafter. Mice of Group III were given a total of three intramuscular injections with $0.2 \mathrm{mg}$ each prednisolone on the day of tumor inoculation, and five and ten days thereafter. Mice of Group $I V$ received consecutive injections with chloroquine phosphate, at a single intraperitoneal dose of $0.2 \mathrm{mg}$ on the day of tumor inoculation and every other day thereafter up to six times in total.

Histological examinations. The experimental animals with one of the above-mentioned tumors transplanted to the back were kept on regular mouse food and water ad libitum and sacrified at intervals. The tumor was removed together with adjoining tissues, of which multiple sections were made and stained with hematoxylin-eosin and Azan-Mallory stains. On examination of these histological specimens, particular attention was focused on the growth pattern of the tumor at its advancing margin, including the quantity and quality of 


\section{Results}

\section{Mammary carcinoma}

Preliminary examination of the control cases (Group I) disclosed that histologic appearance of the advancing margin of this tumor was a matter of considerable individual variation even within untreated animals. However, in the majority of the cases of this group, the tumor had fairly well defined boundaries, which rarely showed sprouting, and a thin layer of connective tissue was commonly seen outside and adjacent to the tumor margin (Fig. 1). Such a pattern was considered as representing a standard growth picture of this tumor and designated the 'standard' pattern.

With such background, the specimens of all groups were examined case by case, in a randomized order, and the finding was classified into one of the following three categories: (1) the standard pattern, (2) the 'less infiltrative' pattern in which the tumor margin was sharply defined showing an expansive aspect and the peritumoral connective tissues thicker and denser than in the standard pattern, and (3) the 'more infiltrative' pattern in which the tumor margin appeared to be more infiltratively growing than in the standard pattern as evidenced by active sprouting of nets of tumor cells lacking in reactive proliferation of perifocal connective tissues. Typical examples of the less infiltrative and the more infiltrative patterns are given in Figs. 2 and 3.

Table 1 shows the frequency distribution of these three basic patterns in the above-mentioned four experimental groups. The less infiltrative pattern was encountered in Group II (typhoid vaccine) quite commonly, while the more infiltrative pattern was predominant in Groups III (prednisolone) and IV (chloroquine).

TABLE 1. Morphological pattern of the advancing margin of subcutaneously transplanted mammary carcinoma in variously treated recipients*

\begin{tabular}{|c|c|c|c|c|}
\hline $\begin{array}{l}\text { Recipients } \\
\text { Days after } \\
\text { transplantation }\end{array}$ & $\begin{array}{c}\text { Group I } \\
\text { (untreated) }\end{array}$ & $\begin{array}{c}\text { Group II } \\
\text { (TA vaccine) }\end{array}$ & $\begin{array}{c}\text { Group III } \\
\text { (prednisolone) }\end{array}$ & $\begin{array}{c}\text { Group IV } \\
\text { (chloroquine) }\end{array}$ \\
\hline $\begin{array}{l}14 \\
29\end{array}$ & $D D D D \times$ & $x \times x$ & $\begin{array}{l}0 \times \\
00\end{array}$ & $\begin{array}{l}D O O \times \times \\
D O O O O\end{array}$ \\
\hline
\end{tabular}

* A semi-closed circle $\bigcirc$ indicates the 'standard' pattern, a closed circle the 'less infiltrative' pattern and an open circle $\bigcirc$ the 'more infiltrative' pattern of this tumor. A cross sign $\times$ shows that the inoculant was not identifiable on histological examination.

\section{Bashford carcinoma 63}

The standard pattern in this tumor as estimated by examination of the connective tissue developing surrounding the tumor. 
control cases (Group I) differed considerably from the standard pattern in the transplanted mammary carcinoma. The tumor boundaries usually were less distinctly definable than in the mammary carcinoma, and spread of free tumor cells into adjoining structures was not uncommon. In short, this tumor grew in untreated mice more infiltratingly than did the transplanted mammary carcinoma. Nevertheless, a layer of reactive connective tissues, though being rather sparse, was identifiable outside the advancing margin of the tumor and this gave a major criterion for characterization of the standard pattern (Fig. 4). The less infiltrative and the more infiltrative patterns were defined as deviations from the standard pattern as in the case of the mammary carcinoma. Examples of these patterns are shown in Figs. 5 and 6.

The results with this tumor are summarized in Table 2. The less infiltrative pattern was encountered exclusively in Group $I I$ (typhoid vaccine). On the other hand, Group III (prednisolone) and IV (chloroquine) consisted of the cases of the more infiltrative pattern with a few exceptions showing the standard pattern.

TABLE 2. Morphological pattern of the advancing margin of subcutaneously transplanted Bashford carcinoma 63 in variously treated recipients*

\begin{tabular}{|c|c|c|c|c|}
\hline $\begin{array}{l}\text { Recipients } \\
\text { Days after } \\
\text { transplantation }\end{array}$ & $\underset{\text { (untreated) }}{\text { Group I }}$ & $\begin{array}{c}\text { Group II } \\
\text { (TA vaccine) }\end{array}$ & $\begin{array}{c}\text { Group III } \\
\text { (prednisolone) }\end{array}$ & $\begin{array}{c}\text { Group IV } \\
\text { (chloroquine) }\end{array}$ \\
\hline 3 & 000 & 00 & $x \times \times$ & 000 \\
\hline 7 & 0010 & 00 & 0000 & 000 \\
\hline 10 & 0000 & 100 & $D O O$ & 0000 \\
\hline 14 & 00 & 01 & 000 & 0000 \\
\hline
\end{tabular}

* ef. Table 1 for legends

\section{Ehrlich ascites tumor}

The advancing margin of this tumor was even more infiltrative than in the case of the Bashford carinoma 63. In fact, in the control cases (Group I), the histologic boundaries of the tumor usually were obscured by diffuse spread of free tumor cells and were surrounded by very poorly developing connective tissues (Fig. 7), and such rather progressive figures formed the standard pattern in this tumor. Examples of the less infiltrative and the more infiltrative patterns in this tumor are shown in Fig. 8 and Fig. 9, respectively.

The frequency distribution of these three patterns in the four experimental groups of mice is shown in Table 3. The majority of Group II (typhoid vaccine) exhibited the less infiltrative pattern, and Group III (prednisolone) mostly the more infiltrative pattern. Although the standard pattern was predominant in Group IV (chloroquine), a considerable proportion of this group showed the more infiltrative pattern. 
TABLE 3. Morphological pattern of the advancing margin of subcutaneously transplanted Ehrlich ascites tumor in variously treated recipients*

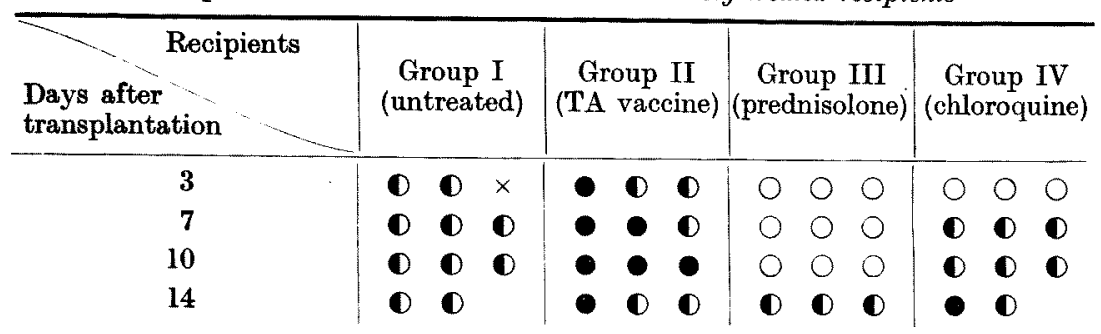

* cf. Table 1 for legends.

\section{Discussion}

The CPL classification, which was proposed by $\mathrm{Imai}^{2}$ and was based on the mode of growth of carcinoma at its advancing margin, has been accepted by many Japanese researchers as a reliable indicator of the postoperative prognosis in tumors of various organs. ${ }^{3}$ In their analytical study of the end results of gastric resection for carcinoma of the stomach, Muto et $a l .{ }^{4}$ of our department confirmed that this classification indicated the prognosis more accurately than did conventional histopathological classifications of the tumor. These clinical facts clearly show that the morphological pattern of the advancing margin of carcinoma provides a dynamic estimate of its growth capability. The present experiments aimed at elucidation of the factors that determine the morphological pattern of the advancing margin of carcinoma. In fact, it appears to be a very interesting problem whether the pattern of the advancing margin is purely inherent to the tumor or is significantly influenced by conditions of the host. This was examined in combinations of three different tumors and four different conditions of the host. Among the drugs used in this experiment to modify the host condition, typhoid vaccine and prednisolone were chosen because of their characteristics to alter the activity of the reticuloendothelial system, a probable factor of the host defense mechanism, and their appreciable effects on the metastasis formation as we confirmed in the preceding experiment, ${ }^{1}$ and chloroquine in view of its well-established effect to inhibit fibrogenesis.

The results of the experiment may lead to the conclusion that the morphological pattern of the advancing margin significantly varies with the kind of the tumor but at the same time is considerably influenced by the condition of the host. The three transplantable tumors examined in this experiment showed clearly distinguishable growth patterns; the tendency toward infiltrative growth, as manifested by obscured tumor boundaries, sprouting of cell nests not accompanying reactive proliferation of peritumoral connective tissues, spread of free tumor cells, etc., was in the descending order of intensity of Ehrlich ascites tumor, Bashford carcinoma 63 and the $\mathrm{C} 3 \mathrm{H}$ mammary carcinoma. This indicates the 
kind of the tumor as being a principal determinant of the mode of progress. But, common to these three kinds of tumors, the growth was morphologically less infiltrative in animals treated with typhoid vaccine and more infiltrative in those treated with prednisolone or chloroquine than in untreated control animals. It is thus apparent that the growth pattern of the transplanted tumor is subject to considerable change according to the condition of the host.

The mechanism by which the treatments of the host altered the growth pattern of the transplanted tumors is beyond the scope of this investigation. However, informations on the interaction between neoplasia and the reticuloendothelial function of the host ${ }^{5,6}$ are very suggestive as regards this problem. It has been shown that stimulation or inhibition of the reticuloendothelial function of the experimental animals leads to an increased or decreased resistance, respectively, against the challenge of neoplasms. For instance, prior infection of rats or mice with Baccillus Calmette-Guérin, which causes activation of the reticuloendothelial system of these animals, has proved to retard the growth of a variety of transplanted tumors, increase the rate of their regression, and/or prolong the life-span of the recipients. ${ }^{7-9}$ The effect of typhoid vaccine to enhance the reticuloendothelial activity of mice and consequently restrict the growth of a subcutaneously inoculated isologous tumor (MH 134) was confirmed by Suzuki ${ }^{10}$ of our laboratory. Also in the clinical field, the reticuloendothelial activity of the patient with gastric carcinoma was correlated to the morphological character of the tumor, such as the mode and extent of progress and the grade of proliferation of peritumoral connective tissues, and to the prognosis of the patient. ${ }^{11,12}$ In the light of these observations, it appears probable that the change of the growth pattern of the advancing margin of the transplanted tumors as revealed by the present experiments is significantly concerned with the altered activity of the reticuloendothelial system in the host.

\section{Conclusion}

It has been demonstrated experimentally that the morphological pattern of the advancing margin of the transplanted tumor depends largely upon the kind of the tumor but is also significantly modified by the condition of the host.

\section{References}

1) Yamaguchi, I., Takahashi, T., Narisawa, T. \& Hiroki, T. An experimental study on the effect of reticuloendothelial activity on metastasis and recurrence of tumor. Tohoku J. exp. Med., 1965, 87, 338-350.

2) Imai, T. The growth of human carcinoma, a morphological analysis. Fukuoka acta med. (Jap.), 1954, 45, 72-102.

3) Imai, T. Growth patterns in human carcinoma. Obstet. and Gynec., 1960, 16, 296308.

4) Muto, M., Majima, S., Yoshida, K., Karube, K., Teshima, T: \& Yamaguchi, I. 
Factors influencing the end-results of gastrectomy for stomach cancer. Tohoku $J$. exp. Med., 1963, 81, 279-296.

5) Stern, K. The reticuloendothelial system and neoplasia. In: Reticuloendothelial Structure and Function, edited by J.H. Heller, Ronald Press Co., New York, 1958, pp. 233-258.

6) Old, L.J., Benaceeraf, B., Clarke, D.A., Carswell, E.A. \& Stockert, E. The role of the reticuloendothelial system in the host reaction to neoplasia. Cancer Res., 1961, 21, 1281-1300.

7) Halpern, B.N., Biozzi, G., Stiffel, C. \& Mouton, D. Effet de la stimulation du système réticulo-endothélial par l'inoculation du bacille de Calmette-Guérin sur le développement de l'épithélioma atypique T-8 de Guérin chez le rat. C.R. Soc. Biol. (Paris), 1959, 153, 919-923.

8) Biozzi, G., Stiffel, C., Halpern, B.N. \& Mouton, D. Effet de l'inoculation du bacille de Calmette-Guérin sur le développement de la tumeur ascitique d'Ehrlich chez la souris. C.R. Soc. Biol. (Paris), 1959, 153, 987-989.

9) Old, L.J., Clarke, D.A. \& Benacerraf, B. Effect of Bacillus Calmette-Guérin infection on transplanted tumors in the mouse. Nature (Lond.), 1959, 184, 291-292.

10) Suzuki, S. An experimental study on the funetion of the reticuloendothelial system and tumor growth. Tohoku Igaku Zassi (Jap.), 1962, 65, 289-300.

11) Yamagata, S. Reticuloendothelial system in clinical medicine. Proc. Jap. Soc. R.E.S. (Jap.), 1962, 2, 2-14.

12) Omori, Y. Cancer progress and reticuloendothelial system, with special reference to gastric cancer. Proc. Jap. Soc. R.P.S. (Jap.), 1963, 3, 47-55. 


\section{Explanations for Figs. 1-9}

Fig. 1. Standard pattern of the advancing margin of subcutaneously transplanted mammary carcinoma. Twenty-nine days after transplantation to a mouse in Group I (untreated), Azan-Mallory stain. A, $\times 25 ; \mathrm{B}, \times 60$. The boundaries of the tumor are well defined and surrounded by moderately developing peritumoral connective tissues.

Fig. 2. Subcutaneously transplanted mammary carcinoma showing a 'less infiltrative' advancing margin. Fourteen days after transplantation to a mouse of Group II (typhoid vaccine treated). Azan-Mallory stain. A, $\times 25 ; \mathrm{B}, \times 60$. The tumor shows clear boundaries and is embedded in thick and dense connective tissues.

Fig. 3. Subcutaneously transplanted mammary carcinoma showing a 'more infiltrative' advancing margin. Fourteen days after transplantation to a mouse of Group IV (chloroquine-treated). Azan-Mallory stain. A, $\times 25 ; \mathrm{B}, \times 60$. The tumor is actively invading subcutaneous fatty tissues with sprouts of cell nests. Reactive connective tissues are hardly seen around the tumor.

Fig. 4. Standard pattern of the advancing margin of subcutaneously transplanted Bashford carcinoma 63. Seven days after transplantation to a mouse of Group I (untreated). Azan-Mallory stain. $\times 60$. The tumor is infiltrating to adjoining muscles but a thin layer of reactive connective tissues is seen just outside the advancing front.

Fig. 5. Subcutaneously transplanted Bashford carcinoma 63 showing a 'less infiltrative' advancing margin. Seven days after transplantation to a mouse of Group II (typhoid vaccine-treated). Azan-Mallory stain, $\times 60$. The tumor boundaries are relatively well defined and surrounded by a sparse but clearly discernible layer of reactive connective tissues.

Fig. 6. Subcutaneously transplanted Bashford carcinoma 63 showing a 'more infiltrative' advancing margin. Seven days after transplantation to a mouse of Group III (prednisolone treated). Azan-Mallory stain, $\times 60$. Tumor cells are freely invading the muscle fibers without showing definitely formed boundaries. Reactive proliferation of connective tissues is not seen in peritumoral areas.

Fig. 7. Standard pattern of the advancing margin of subcutaneously transplanted Ehrlich ascites tumor. Ten days after transplantation to a mouse of Group I (untreated). Azan-Mallory stain, $\times 60$. Infiltration of the tumor to adjoining structures is remarkable and the development of peritumoral connective tissues is very poor.

Fig. 8. Subcutaneously transplanted Ehrlich ascites tumor showing a 'less infiltrative' advancing margin. Ten days after transplantation to a mouse of Group II (typhoid vaccine treated). Azan-Mallory stain, $\times 60$. The tumor boundaries are fairly well defined and surrounded by a thin layer of reactive connective tissues.

Fig. 9. Subcutaneously transplanted Ehrlich ascites tumor showing a 'more infiltrative' advancing margin. Ten days after transplantation to a mouse of Group IV (chloroquine-treated). Azan-Mallory stain, $\times 60$. The tumor has involved the muscles and is infiltrating to adjoining connective tissues. The peritumoral areas are absolutely negative of reactive connective tissues. 

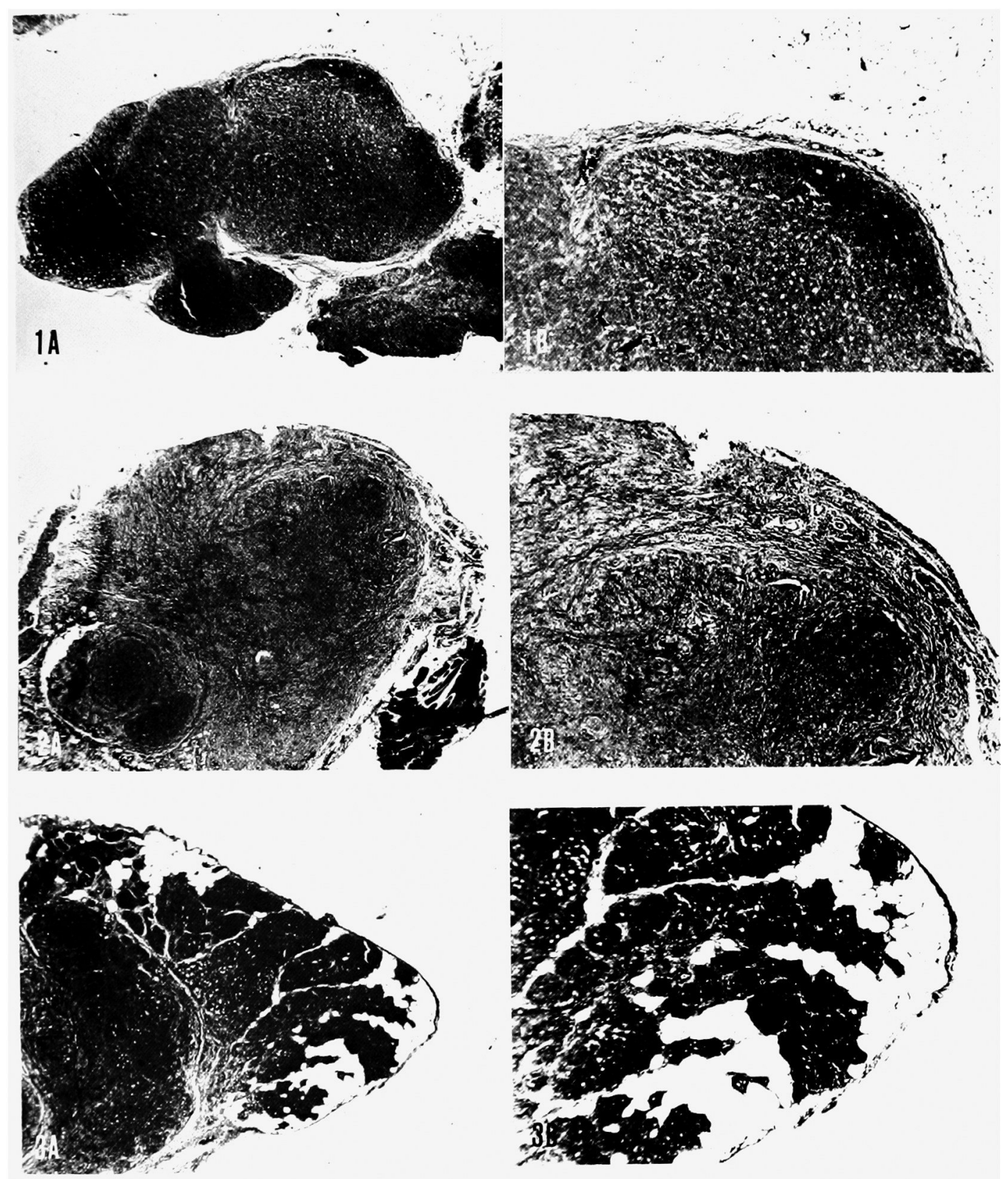


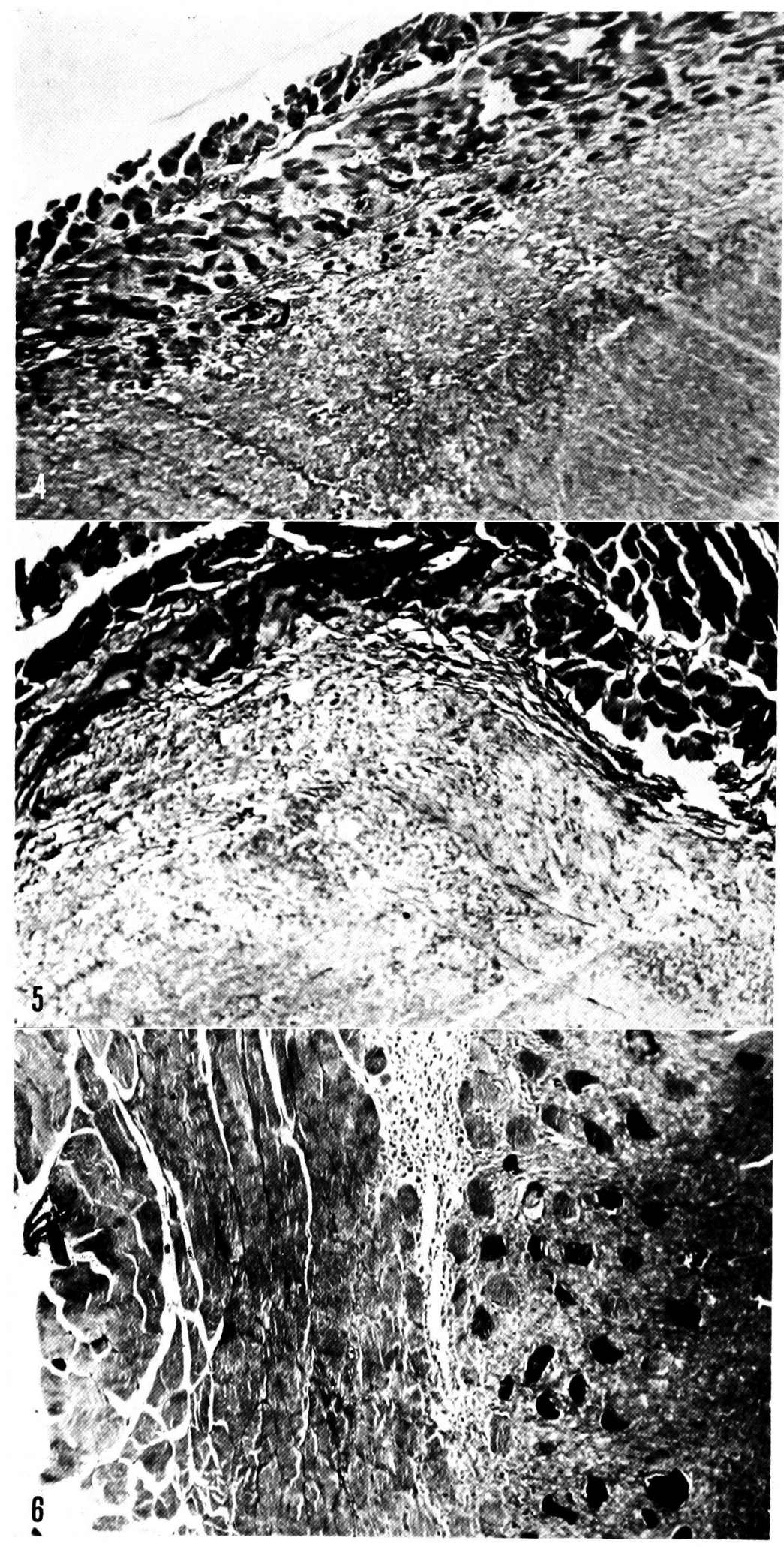




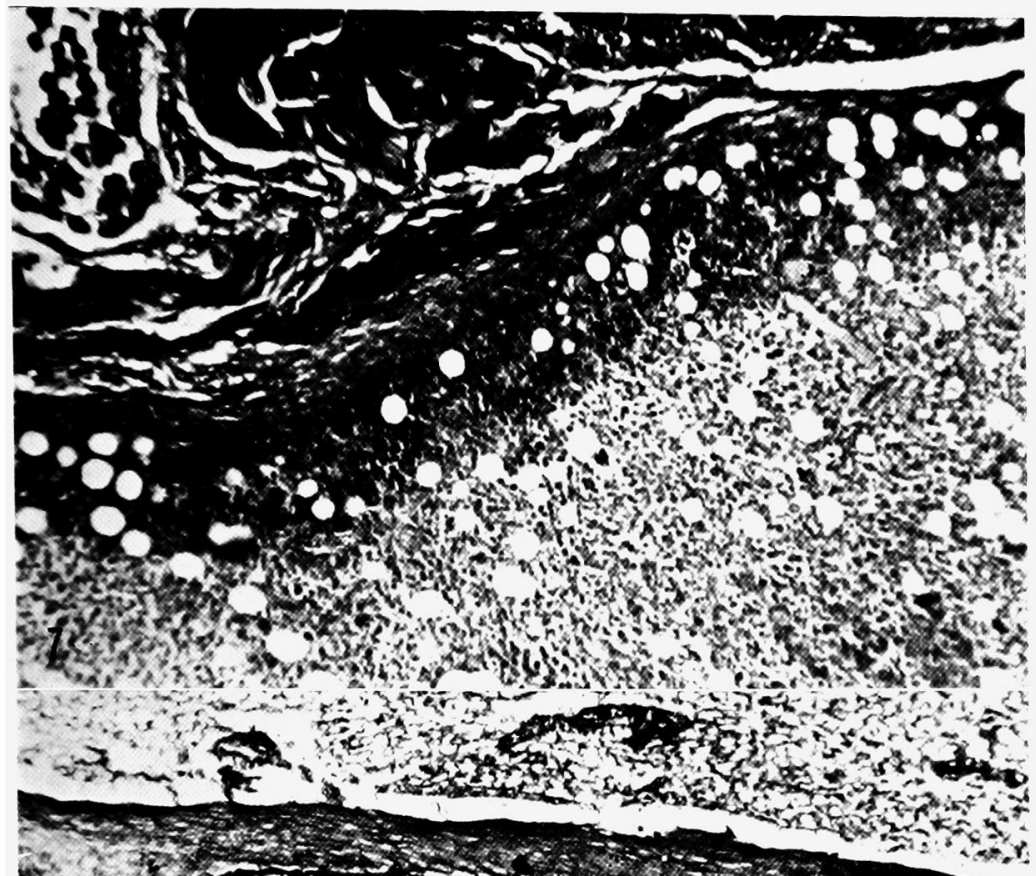

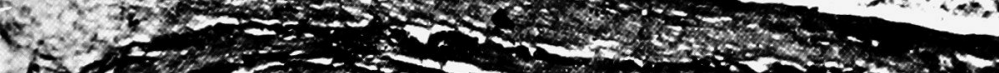

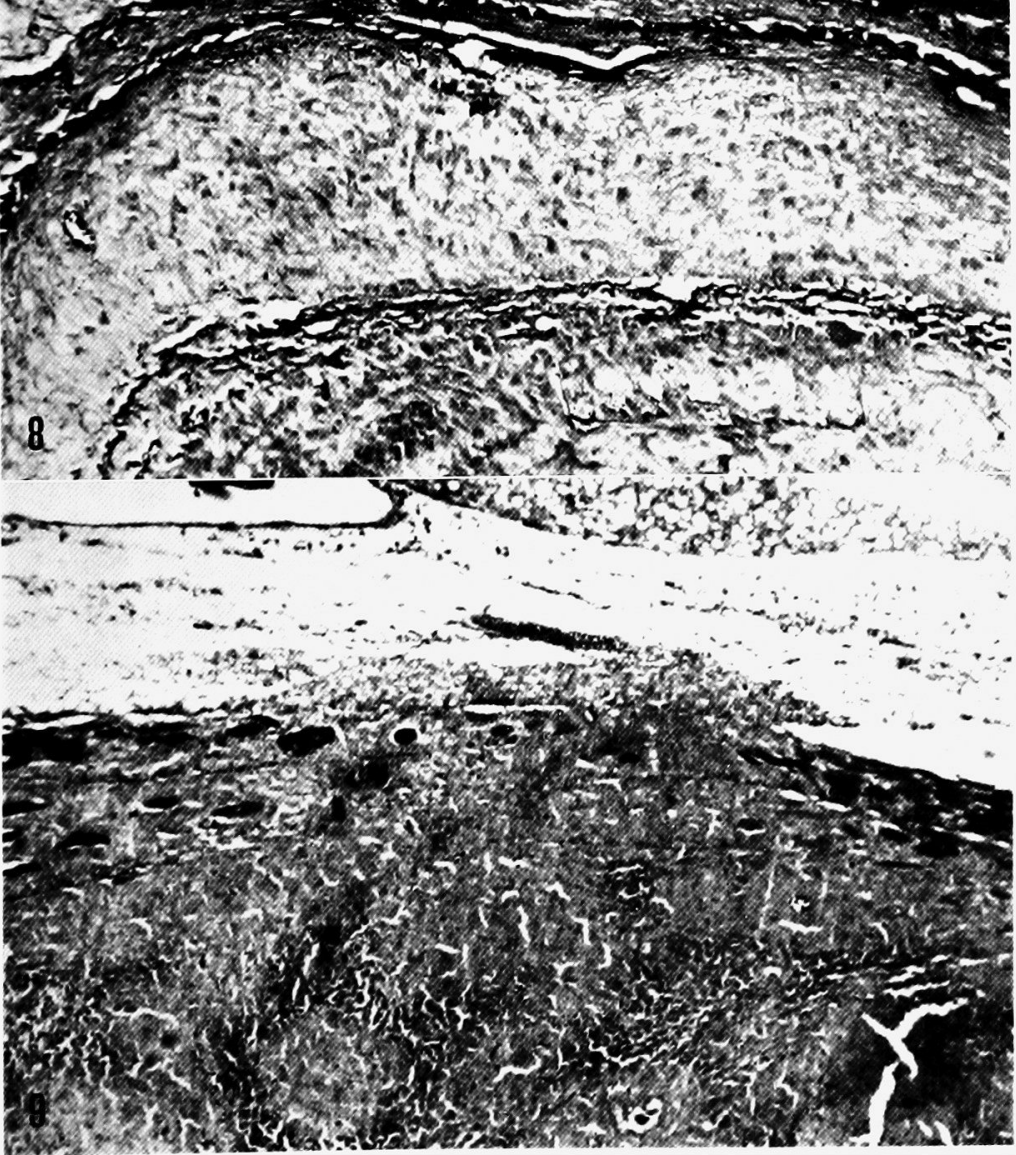

